\title{
Analysis of the Musical Characteristics of Berlioz Fantasy Symphony
}

\author{
Zhiyong Sun
}

Baicheng Normal University, Baicheng, Jilin, 137000

Keywords: Berlioz fantasy symphony; musical characteristics

\begin{abstract}
Berlioz is an important composer, theoretician, and conductor in the French Romantic Period, and one of the most important composers in the history of European music in the 19th century. Berlioz is a romantic and passionate player who is a pioneer composer of the title symphony of the Romantic period. Throughout his life, he has experienced rough times. The failure of two marriages and the loss of his son's pain made him feel extremely lonely in his life. Uncertainty in work and economic income cannot be guaranteed. He could only rely on writing and music reviews to obtain meagre income. However, Berlioz's works combine the essence of romanticism, unconventional style, and give us a new sense of hearing. He promoted the title music, innovatively used "fixed music thinking" in his "Fantasy Symphony" and expressed the idea of poetry and literature with the image of music. He is the creator of a new type of title symphony.
\end{abstract}

\section{Introduction}

"Fantasy Symphony" is a representative work of Berlioz and is a very important symphony in the history of European music. This work introduces titles in music in a unique way. After the appearance of this symphony in 1830, it caused great repercussions in the society at that time. Due to the sentimentality of the composer's character and his passion for creative writing, the basic characteristics of the classical period were broken in the structure of the works, and the form of the creation changed. Create a brand-new musical language style and boldly use titles before each chapter of the symphony so that the text description and the language of the music are perfectly combined, giving the listener a dual feeling of language and language. The symphony of the entire structure, modulation, coordination and harmony, etc. have carried out bold creative writing, creating a new language style of the title music of the Romantic period.

\section{The Creative Techniques of "Fixed Music"}

In Fantasy Symphony, the content of the whole song is determined by a dominant motive "fixed music thinking." The melody image of love appeared in the first movement. In the following four movements, the theme of "fixed music" reappeared, but there was a difference in appearance and processing. This is Berlioz's contribution to the creative writing of music forms and the design of the structure.

Through the analysis of the material of the five movements "Fixed Music", it can be concluded that the composer is using literary thinking to create. For the description of the literary scene, the structure of music is difficult to reach the scale of the classical period. The composer wants to use the sonata type, but does not want to completely detach. Produce a contradictory psychological feature.

Music creation itself should follow its own development laws, literature or other factors can help composers to create and inspire creativity. The process of music creation and the arrangement of structural forms should follow a natural development. The composer should not design the form structure in advance. After setting it in advance, it should follow the basic principles of structure. Obeying the principle must limit the description of the music language and even undermine the mobile development of music. From the perspective of the history of the development of symphony, Berlioz is not the creator of the title music, but he has created a new creative idea for the title symphony. The design of the structure of the "Fantasy Symphony" makes this work unique in the 
history of music, for the new The formation of symphonic direction of development has an important role!

\section{The Flexible Layout of the Musical Structure}

The structure of the "Fantasy Symphony" was completely designed and arranged in accordance with the needs of the development of the plot. The symphony for the Classical period was four movements, and this structural layout has been established. The "Fantasy Symphony" created by Berlioz is composed of five movements, and the order of the movements is also very special. Behind the first movement of sonatas is a brilliant, cheerful waltz, followed by a picturesque pastoral. Style, followed by more bizarre marches, the last question, with the scenes of fantasy, grotesque, feast as the end of the whole song. The connection between the multi-theme and multi-structure arrangement of the work and the "fixed music" is close, but "fixed music thinking" is only the basic material. The composer uses "fixed music thinking" in each movement while at the same time The emergence of new materials and active development has made the performance of music content more abundant.

Through the analysis of the structure of the five movements, we can see that the second movement uses a typical trilogy, and the layout of the melodic structure was established according to the principle of trilogy. The structure of several other movements is no longer typical. The first movement mainly focuses on the theme of lovers of fixed music. Berlioz describes the use of the sonata in dusk, but it is not a sonata in the real sense. The theme of the main department uses the material of "fixed music thinking", the vice department uses the material of a single theme, and the reproduction department must be the reproduction of the vice department in the typical sonata form. It is not here. Berlioz made a new arrangement. Do not follow the principle of regression of tune. The third chapter of the herdsmen's movement uses a flexo, and the type of the song is a three-segment. There is no return to tone.

The reason why composers use non-strict types of musical structure is mainly to arrange the plot of the work. The story and description are the main factors of this work. Set according to the literary title, the music structure is more free. Subject to the development needs of the title and plot.

\section{The Innovative Use of Music Language}

Berlioz's personalized music language is reflected in the Fantasy Symphony. Motivational themes are often composed of three aspects: rhythm, tone, and harmony. It has a dominant significance in the composition of the work. It is the main material for unfolding music. In particular, composers in the Romantic period were better at using this method of composing. In classical times, the recurrence of motives and the development of themes were often constrained by formalism. Berlioz, as one of the most famous composers of French romanticism in the nineteenth century, boldly reformed and created symphony and orchestral works with titles. His creation is not limited to genre, he is good at grasping the progress of melodic lines, uses few motivations as the theme, and maintains coherence among the movements. This kind of creative method is vividly verified in the "Fantasy Symphony".

Through the analysis of the structure of "Fantasy Symphony", it can be seen that Berlioz is deeply influenced by romanticism. In the expression of music language, the use of harmony has both common features and its own unique language style. A harmonized language that tries to get rid of the specific mode of thinking and the fixed potential during the Classical period. During this period, the composers tried to try individualized harmony, which made the harmony style of this period more diversified. The color features are often used, free half frequency appears, and the composite sound of the chord changes its structural color, resulting in special effects. Changes in the tone in the pursuit of a balanced relationship, so that the size of alternating often appear.

In terms of the orchestration, Berlioz cleverly developed his talents and used the instrumental method skillfully to formulate individual colors, making the Fantasy Symphony full of youthful vitality. He has made great efforts on orchestral instruments, expanding the band's production, 
increasing the number of percussions, adding bass clarinets, and more. He developed orchestral colors in a revolutionary manner. Instead of simply pursuing the preparation of two harp, a British tube, etc., each instrument is required to complete something that was previously not dared or completed. He completely proceeded from reality, using the characteristics of each part of the voice, the delicate combination of timbre, strength, etc. to create the orchestral sound, this method has a qualitative difference with the classical period. While giving the audience a new sense of hearing, it also provides the performer with different color thinking. This makes the music tense and dramatic, and its expressiveness and appeal are also enhanced. The music is rich, delicate and innovative.

Through the analysis of the musical characteristics of the "Fantasy Symphony", Berlioz can feel a clever arrangement between the imaginative theme and the unfolding of music. The poetic image and the musical expression match each other at every point. Headlines and forms have never been inconsistent. The melody evolves at its natural pace, all of which have a satisfyingly balanced beauty. The symphonies written by Berlioz, the forerunner of Orchestration, have a great difference from the past. Regardless of the scale of music, the development of music, or the number of movements, the creative method is like a wild horse that is dislocated. It is completely free from the shackles of its predecessors, and is free to sway.

The "Fantasy Symphony" by French composer Berlioz is not only his personal masterpiece, but also an extremely important musical work in the history of music.

\section{References}

[1] On the "Tragicness" of Berlioz Music [D]. Huang Liang. Wuhan Conservatory of Music 2010

[2] On the techniques and techniques of Berlioz Music [D]. Xie Qing. Yunnan Arts Institute 2010

[3] Comparative study and reflection on Berlioz and Liszt's title music concept[D]. Wang Yang. Xi'an Conservatory of Music 2008 